\title{
El presupuesto participativo un reto para el desarrollo local en Cuba
}

\author{
Oscar Hechavarria \\ Universidad de Oriente
}

\section{Resumen}

Lograr que los municipios cubanos cuenten con determinada autonomía financiera para su propio desarrollo y vincular de manera activa a los ciudadanos en el manejo del presupuesto municipal son necesidades latentes que comprometen la efectividad del nuevo modelo económico que el país se ha proyectado. La Ley 113 del 2012 dipuso aplicar la contribución territorial para el desarrollo local, a los efectos de la norma, los municipios cubanos acceden a un presupuesto para poder sustentar la política de desarrollo local; pero contradictoriamente no han aparecido los mecanismos para involucrar a todos los ciudadanos en la aprobación, ejecución y control de este presupuesto y del resto de los recursos públicos. En este sentido, el presente trabajo propone un procedimiento para darles participación a los diferentes actores de la sociedad cubana en el diseño, aprobación, ejecución y control de los fondos públicos municipales. Teóricamente la propuesta se fundamenta en la metodología del Presupuesto Participativo de Porto Alegre, aunque su implementación práctica se ajusta a la realidad cubana.

Palabras clave: Descentralización, desarrollo local, presupuesto participativo, participación ciudadana.

\section{Participatory budgeting challenges local development in Cuba}

\begin{abstract}
To achieve that the Cuban municipalities have certain financial autonomy for their own development and to link from an active way to the citizens in the municipal budgetary procedure is a latent necessity that commits the new economic model's effectiveness that the country has been projected. Aided in The Law 113 of the 2012 you began to apply the territorial contribution for the local development to such effects the Cuban municipalities they have a budget to be able to sustain a politics of local development; but contradictorily the mechanisms have not appeared to involve all the citizens in the approval, execution and control of the treasury and of the rest of the public resources. In this sense the present work proposes a procedure to give participation to the different actors of the Cuban society in the approval execution and control of the municipal public funds. Theoretically the proposal is based in the well-known pattern as Participative Budget of I Behave Cheerful, although its practical implementation responds appropriately to the Cuban reality.
\end{abstract}

Keywords: Decentralization, local development, participative budget, citizen participation .

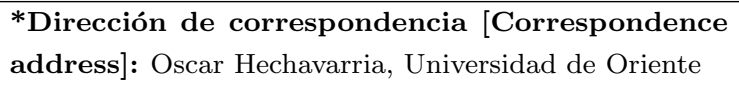




\section{Introducción}

El desarrollo local, visto desde su dimensión política, implica asumir un nuevo modo de estructuración de los órganos de gobierno, de la manera en que se redistribuye el poder y se establecen las relaciones entre los órganos centrales y los locales y entre estos y la sociedad civil. Cuando se habla de desarrollo local hay que transitar ineludiblemente por el tema de la descentralización y la participación ciudadana y con especial acápite por el tema de la descentralización política y económica.

En materia de descentralización y participación ciudadana, en la década del 80, la municipalidad brasileña de Porto Alegre fue partícipe de la puesta en práctica del Presupuesto Participativo (PP). Mediante esta práctica se constituyó un espacio de participación ciudadana para el control y ejecución de los fondos públicos en los municipios. Con el transcurso de los años la experiencia fue perfeccionándose y generalizándose y en la actualidad existe toda una teoría acerca del Presupuesto Participativo (PP) y una amplia diversidad metodológica.

En este sentido el alcance de los gobiernos locales cubanos en la búsqueda de ingresos para su desarrollo, adquiere una mayor dimensión a partir de que la nueva Ley del Sistema Tributario (Ley 113/2012) grava los ingresos de las empresas, sociedades mercantiles y cooperativas con vistas a que tales aportes financien parte de los proyectos de desarrollo local en los municipios.

Desde esta perspectiva se rompe con más de tres décadas de política centralista y verticalista y se avanza hacia relaciones de gobierno más horizontales. Sin embargo la situación se torna verdaderamente paradójica cuando se constata que los actores locales no cuentan con espacios de participación que les permita controlar y tomar decisiones con respecto a este presupuesto. El presente trabajo propone un procedimiento sustentado en una metodología de un amplio reconocimiento internacional: el Presupuesto Participativo de Porto Alegre.

\section{El presupuesto participativo: un reto para el desarrollo local en Cuba}

La propuesta del Desarrollo Local como alternativa para lograr el desarrollo de las naciones engloba en sus fundamentos teóricos el ideal participativo. Se propone un modelo fundamentado, desde el punto de vista sociopolítico, en la incorporación de los diferentes agentes locales (económicos, políticos, ciudadanos) en el proceso de desarrollo. Una concepción del desarrollo como crecimiento humano que resalta el capital social, lo participativo, lo cultural y lo local como factores claves del proceso.

"En el momento actual, las políticas de desarrollo local amplían el protagonismo y las acciones a otros grupos de la sociedad local. Ante todo, los agentes públicos locales, que representan a la sociedad local en los sistemas democráticos, asumen por primera vez la responsabilidad de participar activamente en la definición y ejecución de las estrategias de desarrollo económico local" (Vázquez Barquero, 2000:27).

El desarrollo local sustenta una nueva concepción democrática, cimentada, ya no en una cuestión estrictamente política de conformación y estructuración de los órganos de poder, sino más bien centrada en el acompañamiento a los gobiernos en la conformación ejecución y control de las políticas públicas que impulsan el desarrollo y la construcción conjunta del bienestar deseado. Este enfoque considera el territorio como el referente principal y destaca la necesidad de que los recursos dispuestos por las políticas lleguen a quienes los necesitan, que existan verdaderas políticas territoriales y mayor participación de los actores locales (Gallichio, 2004).

La perspectiva localista considera que el potencial desarrollador de una región no está determinado únicamente por factores económicos en tanto es de considerar que los procesos políticos y sociales condicionan los procesos económicos. En este punto Gallichio (2010:5) ha reiterado que "(...) el desarrollo local es un proceso mucho más sociopolítico que económico en sentido estricto. Los desafíos son mucho más políticos, de articulación de actores y capital social, que de gestión local o de proyectos productivos". Ciertamente el despegue de las capacidades productivas, financieras, innovadoras e industriales no dependen únicamente de una lógica económica, responden igualmente a una lógica social, cultural y política (Esparcia y Escribano, 2014).

En este sentido el Programa de Naciones Unidas para el Desarrollo (PNUD) considera el desarrollo local como: "Un modelo de gestión políticoadministrativo de carácter integral que articula gobierno y sociedad local, que promueve la innovación en lo organizativo institucional, en lo económico como en lo social, teniendo como objetivo un proceso de transformación que tiende a generar condiciones de mayor equidad, sustentabilidad, gobernabilidad y participación" (PNUD, 1997:198).

Desde esta perspectiva un papel relevante lo ocupan los actores territoriales, por la capacidad de 
decisión que pueden tener en las inversiones, en la elaboración y colocación de sus proyectos. El desarrollo se hace depender de la capacidad de las localidades y de sus miembros para darse un proyecto de progreso, de desarrollo y llevarlo a vía de hecho.

La descentralización es otro de los procesos que paralelo al desarrollo local ha venido abriéndose paso. Si el desarrollo local se considera, según hemos argumentado, como un proyecto común de concertación entre actores de una localidad donde la participación ocupa un lugar central, sin equívocos la descentralización es uno de los procesos políticos de importancia para el desarrollo local por lo que aporta en pos de la efectiva participación ciudadana y en la generación de espacios de interacción entre los diferentes actores locales y entres estos y el gobierno local. En este aspecto Enrique Gallicchio y Alejandra Camejo (2005:26) son bastante enfáticos cuando plantean: "(...) el avance y consolidación de los procesos de descentralización se ha vuelto fundamental para el desarrollo local en tanto instrumento para el empoderamiento de las sociedades locales".

La descentralización a la luz de las más modernas conceptualizaciones implica dotar a las localidades de suficientes capacidades que les facilite la toma de decisiones política y administrativa a nivel local y explotar con determinadas libertades las capacidades endógenas de desarrollo. Al respecto un conceptos muy alegórico es el de Alberto Enríquez cuando plantea que la descentralización es "(...) proceso ordenado y progresivo de transferencias de competencias, responsabilidades, poder de decisión y recursos desde el gobierno central a las entidades subnacionales, así como la apertura de ésta a la participación activa de la sociedad civil, que incluye, en consecuencia, la construcción de todas las capacidades necesarias en las entidades subnacionales".

\section{Los defensores de la descentralización lo hacen fundamentalmente desde dos enfoques.}

\section{Enfoque político}

El enfoque político de la descentralización se sustenta en el principio de organizar el poder democráticamente. El fundamento primario de la descentralización desde una óptica política reside en el principio de que todos tienen derecho a participar en el gobierno del Estado. Tocqueville (1984), a quien se le considera la paternidad de estas ideas, planteaba que la comuna es la forma de organización primaria del Estado donde todos tienen la posibilidad de participar directamente y atender lo que todos consideran necesario para la comunidad.
El enfoque estrictamente político reconoce que la descentralización es una forma de redistribución del poder y esto solo puede lograrse transfiriendo poder de decisión desde la administración central a órganos locales y democráticamente electos (Palma, 1989).

Según Jordi Borja (1987), un importante defensor de la descentralización desde la perspectiva política, lo fundamental de la descentralización es promover la participación política y social y esto requiere necesariamente de ámbitos territoriales reducidos y proximidades entre los interlocutores, pero sobre todo un reconocimiento legal de esos espacios territoriales.

Palma (1983) otro importante exponente de esta posición considera que no existe un principio de descentralización si los entes descentralizados no son elegidos democráticamente y destaca tres aspectos de gran importancia para cualquier proceso de descentralización:

- La institucionalización (órganos dotados de competencias y provistos de recursos).

- La autonomía para designar las autoridades en al ámbito de su competencia política y jurídica y disponer de los recursos. Para que exista descentralización política no basta transferir competencias administrativas a gobiernos electos es necesario que dichas competencias sean ejercidas autonómicamente (Finot 2001).

- Desconcentrar administrativamente niveles necesarios de recursos.

\section{Enfoque político-administrativo}

Este enfoque se fundamenta en la incapacidad de los gobiernos centrales para asumir con eficiencia la actividad de los servicios. En la actualidad los gobiernos centrales tienen limitaciones para ofrecer respuestas a las demandas de los diferentes sectores de la población, demostrando incompetencias e insuficiencias no solo para resolver, incluso para conocer problemáticas sociales, políticas y económica que resultan más complejas y diversas. Es por ello que se recurre a los gobiernos locales, las empresas privadas y las organizaciones no gubernamentales en busca de mayor eficiencia (Finot, 2001). A tales efectos la descentralización se amplia al sector administrativo y comienza a ser utilizada como un instrumento político administrativo.

Se considera entonces que "(...) la descentralización modifica el aparato institucional políticoadministrativo, trasladándose competencias a uni- 
dades inferiores (funcional o territorialmente definidas) dentro del aparato estatal, o bien a instituciones fuera del Estado" (Von Haldenwang, 1990: $62)$. En este sentido la descentralización puede ser administrativa, económica y política:

- La descentralización administrativa apunta al aumento de la "eficiencia" en la asignación y apropiación de recursos por parte de las administraciones nacionales.

- A través de la descentralización económica se quiere limitar las funciones estatales de regulación económica y de distribución social, aliviando de esta manera el presupuesto del Estado.

- La descentralización política tiene como fin primario crear nuevas vías para la participación política al nivel local o regional.

En síntesis desde ambas perpectiva la descentralización es un proceso esencial del desarrollo local, que lo potencia y facilita la profundización democrática (Cárdenas, 2002). La descentralización obliga a los gobiernos centrales a redistribuir competencias, facultades y recursos a los gobiernos regionales habida cuenta de que en el seno de los gobiernos locales y regionales está fomentada la capacidad para lograr el despegue de los proyectos de desarrollo local y la democratización de la sociedad.

La descentralización y el desarrollo local tienen como punto común favorecer la aparición de importantes mecanismos de participación ciudadana que además han tenido un importante catalizador en los procesos de cambios políticos y sociales acaecidos en las dos últimas décadas.

Los ya citados autores Gallicchio y Camejo (2005) nos recuerdan que la descentralización, especificamente en América Latina, es una respuesta a las tensiones y conflitos políticos por la incapacidad del Estado para dar respuestas a las demandas de de los ciudadanos y por la falta de canales de participación popular.

De manera que los procesos participativos devienen como respuestas ante una crisis de los modelos de desarrollo que enfatizan en los aspectos económicos y que desconocen los aspectos sociales, políticos, y culturales y del otro lado la profunda crisis participativa por la que atraviesa el modelo político representativo.

De la amplia gama de mecanismos participativos nacidos en las dos últimas décadas el $\mathrm{PP}$ ha sido uno de los más difundidos, al punto que se ha convertido en una referencia para la democracia y el desarrollo local.

\section{El Presupuesto Participativo: un acer- camiento a su metodología}

El PP nace en un municipio de Brasil -Porto Alegre- durante el mandato del Partido de los Trabajadores en el año 1989. El objetivo principal era introducir mejoras en la gestión local de gobierno a partir de que el pueblo decidiera sobre el presupuesto local, que es uno de los aspectos cardinales del enfoque localista del desarrollo.

Este instrumento participativo constituye un ejemplo genuino de participación en el nivel local, por medio del cual los ciudadanos inciden en el destino del presupuesto de su localidad. Aunque es una práctica que nace en el ámbito municipal (Porto Alegre), en su generalización se han desarrollado experiencias de más amplio alcance territorial.

Una de las primeras definiciones del PP reconoce que es un instrumento de participación directa mediante el cual la población discute y decide sobre el presupuesto y las políticas públicas de una localidad. (De Souza y Genro, 1999).

En la medida que la experiencia ha sido generalizada en otros países y en el propio Brasil aparecen definiciones más ajustadas a las nuevas metodologías. En este sentido más que un instrumento de participación directa se considera al PP como una mezcla de participación directa con la representativa, "(...) los presupuestos participativos plantean una idea nueva de articulación en la que la dimensión representativa conserva su idiosincrasia, pero integra formas de participación directa" (Ganuza Fernández y Gómez Fortes, 2008:12). Por otra parte se le considera un proceso cíclico conformado por varias etapas.

El PP significa una revelación práctica para la teoría de la democracia participativa y para el enfoque de desarrollo local en tanto:

Constituye un instrumento de participación que reproduce los más genuinos principios de la democracia participativa en tanto concilia mecanismos de democracia representativa con la participación directa.

Patentiza la efectividad de las políticas descentralizadoras para alcanzar el desarrollo, específicamente las de alcance político y administrativo. Es notable como en la mayoría de los casos la implementación del PP viene acompañado de un grupo de normativas de carácter descentralizador que otorgan a los gobiernos regionales y al pueblo poderes suficientes para decidir sobre el presupuesto público.

En la práctica el PP no ha tenido una unifor- 
midad metodológica y si bien encontramos en los diferentes modelos puntos coincidentes, cada experiencia tiene sus singularidades que dan cuenta de las características económicas, políticas, sociales y culturales e incluso geográficas que distinguen un territorio de otro.

Precisamente la flexibilidad en la implementación ha posibilitado la rápida difusión que a su vez ha provocado una diversidad metodológica que según Sintomer (2005: 3) pueden agruparse en cuatro grandes grupos:

La primera metodología está centrada en el modelo de Porto Alegre. Este modelo ha mostrado una gran solidez en el tiempo y con pequeñas variaciones ha sido difundido en muchos países de América y Europa. Entre sus principales peculiaridades están:

1. Asume el debate público en la base en dos dimensiones (territorial y temática). Se debate paralelamente en base a un principio territorial (barrio, comunidad, cuadra) y con arreglo a problemas precisos (agua, medio ambiente, energía).

2. Articula diferentes niveles territoriales (barrio, sectorial, municipal). Los ciudadanos se integran en asambleas o gremios constituyendo un espacio participativo a nivel de barrio.

3. Carácter cíclico del proceso. El PP es un proceso continuo que se desarrolla a lo largo de todo el año.

4. La participación ciudadana tiene carácter deliberativo.

En la segunda metodología se inscribe como ejemplo típico el de Albacete en España. En esencia sigue un procedimiento similar al de Porto Alegre, pero se distingue en la manera en que los ciudadanos participan como parte de una organización social y no individualmente.

La tercera metodología ha sido muy difundida en Francia. Se centra en los llamados fondos de inversión local. Los ciudadanos teniendo en cuenta el monto de estos fondos a nivel local deciden su utilización en determinadas obras.

La cuarta metodología es la implementada por los jurados ciudadanos. El proceso se centra en un grupo de ciudadanos elegidos para debatir sobre temas relacionados con determinadas problemáticas de la localidad que luego dictaminan al respecto y aunque el dictamen no tiene carácter deliberativo es tenido en cuenta por las estructuras municipales.
A pesar de los diversos esquemas en los que se han desarrollados los presupuestos participativos es posible identificar características que permiten su análisis como parte de una misma familia (Ganuza Fernández y Gómez Fortes, 2008):

\section{- Constituye una práctica participativa local.}

Aunque existen experiencias supramunicipales el ámbito de instrumentación es la localidad, el municipio. Es a nivel local donde la posibilidad de interacción entre el gobierno y los ciudadanos resulta más viable, pero además donde las políticas tienen mayor impacto y reconocimiento (Ramírez, 2009).

- El proceso tiene como objeto los fondos públicos.

Teniendo en cuenta que toda política de gobierno se sustenta financieramente en los fondos públicos, "(...) el presupuesto - como fondo público y plan de acción- se convierte en el mecanismo central del control público sobre el Estado" (Sousa, 98: 113). De ahí que el PP, más allá de constituir un mecanismo de participación y control popular al presupuesto público, es considerado un instrumento que democratiza gran parte de la actividad pública.

Dentro de este punto existen varias tendencia: a) se discute la totalidad del presupuesto, b) se debate acerca de un $\%$ del presupuesto, c) Se debate acerca de los gastos y no de los ingresos.

- Se desarrolla en un espacio de abierto y deliberativo debate entre los ciudadanos.

El espacio de debate abierto, en lo que se ha denominado base de la pirámide, permite la interacción de los ciudadanos en un nivel micro local. Constituye el espacio de participación popular directa donde se congregan a instancias de los propios habitantes, de las asociaciones o de los delegados del PP sin control por parte los órganos de poder, aunque es posible su asistencia desde diferentes niveles para proporcionar información. (Rendón, 2004).

- El proceso tiene un carácter cíclico

El PP se divide en etapas que conforman un ciclo a lo largo del año, se dice que el proceso comienza donde termina. La primera etapa de un ciclo queda enlazada con la última del ciclo anterior, de manera que al iniciarse un nuevo ciclo se le informa al pueblo el estado en que se encuentra la ejecución de las acciones precedentes.

- Combina mecanismos de democracia directa con mecanismos de democracia representativa. 
En el PP los ciudadanos forman parte del proceso en tres niveles: diseño, ejecución y control. En cada uno de estos niveles se propicia la intervención directa de los ciudadanos y aunque paralelamente se introducen mecanismos representativos, la participación directa constituye el núcleo del todo el proceso.

\section{La municipalidad cubana, el presupuesto local y la partici- pación ciudadana.}

El proceso de perfeccionamiento del modelo económico cubano tiene en el desarrollo local una de sus prioridades. Se pretende un modelo donde los municipios tengan mayor autonomía en la gestión y organización de los asuntos económicos, que estos se conviertan en baluartes de su propio desarrollo y de la solución de las distintas problemáticas que se gestan hacia su interior con mayor protagonismo de la ciudadanía en el proceso ${ }^{1}$.

Por tales motivos el municipio en la última década se ha convertido en centro de analisis de la comunidad cientifica y académica cubana (jurista, sociologos, ecnomistas, filosofos) en aras de perfeccionar los procesos municipales.

Según el texto constitucional cubano el municipio es la sociedad local con personalidad jurídica a todos los efectos legales, organizada políticamente por la ley, en una extensión territorial determinada por necesarias relaciones económicas y sociales de su población, y con capacidad para satisfacer las necesidades mínimas locales.

Ada Guzón (2015:113), una importante investigadora de la municipalidad cubana considera que "el municipio es el eslabón esencial en el desarrollo del país, si se tiene en cuenta que constituye el espacio de lo local, de las relaciones interpersonales, donde se alcanzan o no niveles de satisfacción de individuos y grupos, escenario clave donde la sociedad local espera ancontrar respuestas a sus necesidades y aspiraciones económicas, materiales y espirituales y donde transcurre el vínculo más directo entre el pueblo y el gobierno".

La actual estructura política administrativa de los municipios cubanos data de 1976 fecha en que fueron contitucionalizados los órganos locales del poder popular. De esta forma al amparo de la constitución Cubana de 1976 queda juzgada la Asam-

\footnotetext{
${ }^{1}$ Véase lineamientos $20,37,38$ y 113 de la política económica y social aprobados en el VI congreso del Partido Comunista de Cuba, disponible en http://www.prensalatina.cu/Dossiers/ProyectoLineamientosPCC.pdf
}

blea Municipal del Poder Popular (AMPP) como máximo órgano del poder local, investido de la máxima autoridad para ejercer "gobierno" 2 .

Mucho se discute entre los cientitas cubanos con respecto al término gobierno en el nivel local, en el sentido de si realmente debe realizar o realiza la (AMPP) actvidad de gobierno, sin embargo coincidimos con Villavella Armegol (2004) para quien el término se refiere a las acciones que realiza la Asamblea en pos de lograr la fluidez económica política y cultural de la comunidad, lo que implica asumír tareas como: trazar políticas y ejercer el control de las mismas, tomar decisiones, en fin, asumir la dirección de la localidad.

La AMPP es un órgano no permanente y sesiona de manera ordinaria o extrordinaria en fechas precisas del año, teniendo en cuenta que sus miembros no son profesionales.

La AMPP cuenta con un organo que le está subordinado, el Consejo de Administración Municipal $(\mathrm{CAM})^{3}$. Este ente es el encargado de la dirección y control de la actividad pública del municipio y por otra parte ejecuta e implementa los acuerdos tomados por la Asamblea, convirtiéndose así en el ente ejecutivo de la AMPP. Este órgano para su funcionamiento se reúne al menos dos veces al mes. De estas reuniones salen los acuerdos, aprobados por mayoria de sus miembros, que encaminan las actividades del órgano (Villavella Armegol, 2004).

Tanto la Asamblea como su Consejo están presididos por una misma persona que es elegida de manera democrática por los miembros de la AMPP. Esta preceptiva en la práctica ha traido muchos inconvenientes en tanto no se puede ser juez y parte, como expresarían Martha Prieto y Lissette Pérez (2004 a) se produce una confusión de funciones que dificulta el control del organo representativo (AMPP) sobre el ejecutivo (CAM).

La Asamblea es un órgano representativo, constituido por delegados que son elegidos de manera directa por los ciudadanos en la base como genuina expresión de la soberanía popular.

Por otra parte el delegado marca la conexión entre el pueblo y el gobierno municipal en tanto por medio de las rendiciones de cuenta que asume frente a sus electores conoce las problemáticas que afectan a la comunidad y las traslada al ente representativo a la vez que gestiona su solución y da respuesta al electorado. El delegado atúa bajo un madato imperativo de sus electores que lo convierte en su

\footnotetext{
${ }^{2}$ Véase Constitución de la República de Cuba, reformada en 1992 , art. 103.

${ }^{3}$ Véase acuerdo 2564 del 15 de Enero de 1993 el Comité Ejecutivo del Consejo de Ministro de Cuba.
} 
representante ante el órgano de poder. Es por esta vía que se establece el vínculo político jurídico entre el pueblo y el órgano representativo que se complementa con el acto revocatorio que pueden ejercer los mandantes sobre los mandatarios (Villavella Armegol, 2004).

El delegado es considerado la máxima autoridad dentro de su demarcación, con amplias atribuciones, proyección moral y dominio de la realidad comunitaria, entre sus funciones está el deber de rendir cuentas a sus electores al menos dos veces al año sobre su gestión personal en las solución de los problemas de la comunidad.

Mientras tanto la rendición de cuenta es el espacio de mayor democracia en la localidad cubana. La rendición de cuenta es un proceso de un alto contenido democrático en tanto constituye un espacio de debate abierto, de críticas, análisis y propuesta de solución a las problemáticas locales. Es el espacio para proyectar y evaluar el trabajo de la comunidad, por lo tanto marca la posibilidad del pueblo de ejercer gobierno y de ejercer un control social por la vía informativa y publicitaria sobre la propia actividad del delegado y de los órganos de gobierno.

Sin embargo, en los últimos años tanto la rendición de cuenta del delegado a sus electores como la propia actividad del delegado han perdido vigor, probidad y vitalidad siendo objeto de diversas críticas entre las que resaltan (Wanche, 2012):

- Limitada participación de los delegados en la creación de políticas públicas y del presupuesto.

Elevado formalismo en los procesos de rendición de cuenta dado la insuficiente capacidad decisoria del delegado quien se abstiene a efectuar un encargo estatal y no actividad de gobierno y el bajo nivel de solución de los planteamientos formulados a las entidades administrativas

- Incapacidad financiera y de decisión sobre los recursos locales del delegado que limita el ejercicio de sus atribuciones.

Un órgano importante detro de esta estructura es el Consejo Popular. Este órgano se instrumeta dentro los municipios cubanos durante los años 1991- 1993, especificamente en el año 1992 se constitucionaliza. Su instauración se fundamenta en un proyecto de acercar los órganos de gobierno a la comunidad, tocar más de cerca sus problemáticas.

El órgano está compuesto por los delegados de la comunidad, a la cabeza del ente está un presidente y un vicepresidente elegidos de entre sus miembros. El presidente es el único miembro profesional y se subordina al presidente de la Asamblea. Su funcionamiento está señido a actividades de control y de análisis de las problemáticas de la comunidad.

- El presupuesto local, dentro de la organización politica administrativa municipal, es un aspecto medular para su funcionamiento y el cumplimiento de las actividades que le compete al gobierno municipal. Resolver los problemas que demanda una localidad es una tarea gigantesca e implica una solvencia económica y financiera que permita impulsar el desarrollo. "(...) los recursos económicos municipales se convierten en la fuente para la solución de los problemas comunitarios, en tanto son medios que propician la capacidad y la iniciativa concreta del órgano al trazar la líneas para el desarrollo del municipio" (Pérez Hernández y Prieto Valdés, 2004).

Desde esta visión se requiere incentivar dos procesos que están muy interelacionados: capacidad municipal para generar recursos financieros propios y democratizar el proceso de diseño, ejecución y control del presupuesto municipal.

Para la realización y desarrollo de sus actividades, los presupuestos locales a tenor del Decreto Ley 192 cuentan con las siguientes fuentes de ingresos ${ }^{4}$ (Santos Cid y Peralta de Valle, 2003):

- Ingresos cedidos: Provienen de los recursos que aportan las entidades de subordinación local y otros que por su procedencia están asociados a una erogación que tuvo o tiene que realizar la localidad. El ejemplo más claro es el Impuesto sobre la Fuerza de Trabajo, que se cede totalmente a los presupuestos locales, con independencia de la subordinación del contribuyente, ya que es en la localidad donde se formó y se atiende al trabajador y su familia.

- Ingresos participativos: Son ingresos que corresponden al Presupuesto Central y se otorga un tanto por ciento de participación de los recaudados en la localidad, de los cuales la participación se autoriza del Impuesto Sobre Utilidades de las empresas de subordinación nacional y de determinados productos del Impuesto sobre las Ventas y de Circulación.

Esta perpectiva para manejar los ingresos fiscales municipales resulta poco factible para asumir

\footnotetext{
${ }^{4}$ Véase Decreto Ley 142 de la Adninistración Financiera del Estado de 8 de Abril de 1999.
} 
un proyecto de desarrollo local por el nivel de centralismo y verticalismo que encierra ${ }^{5}$. De la letra de la norma puede advertirse que es muy estrecho el margen de decisión que otorgan a los municipios en cuanto a la exacción y disposición de ingresos, en tanto gran parte de los ingresos es cedido y manejado desde los niveles centrales e intermedios de la estructura estatal (Díaz Legón, 2015). Con esta medida se pretende equilibrar financieramente todos los municipios mediante un proceso de redistribución realizado por la intancia provincial. Sin embargo es cuestionable hasta que punto resulta racional y estimulante para incentivar el trabajo de los municipios, que los ingresos generados por ellos sean administrados por el nivel provincial más allá de cualquier pretensión de busqeda de un equilibrio monetario etre los municipios.

En este sentido se precisa primero: fortalecer la capacidad fiscal de los municipios. La perspectiva es facultar a las localidades para incidir en la variación de la politica fiscal que le afecta. Díaz Legón (2015) hace referencia especificamente a que los municipios puedan variar cuestiones como la base imponible o el tipo impositivo.

Como segundo aspecto se debe potenciar la obtensión de recursos financiaros, al menos crear las vías para ello. Los municipios deben contar con un presupuesto creado a partir de los propios esfuerzos y potancialidades del territorio, y que a la vez estimule el trabajo en la medida que esos resultados se traduzcan en prosperidad y nivel de vida para el territorio (Díaz Legón, 2015).

En lo tocante a la elaboración del presupuesto ciertamente es una atribución de las AMPP elaborar la propuesta del presupuesto municipal ${ }^{6}$. Esta propuesta se presenta a la Dirección Provincial de Finanzas y a la Asamblea Provinvial correspondiente y posterior a su evaluación a este nivel se presenta ante el Ministerio de Finanzas y Precios quien a su vez lo analiza y eleva ante la Asamblea Nacional para su definitiva aprobación mediante Ley (Pérez Hernández y Prieto Valdés, 2004). Finalmente, una vez aprobado el presupuesto se le notifica a la dirección provicial de finazas y este lo distribuye por esfera.

En cuanto al control del presupuesto éste comienza desde el mismo inicio de la ejecución del presupuesto. El ejercicio del control se efectúa por los administradores de la unidad gestora y por los niveles superiores mediante comprobaciones de gastos

\footnotetext{
${ }^{5}$ La nueva Ley Tributaria 113 de 2012 en el artículo 314 configura una nueva modalidad que constituye una importante fuente de recursos financieros para el desarrollo local la cual será analizada en otra parte del trabajo.

${ }^{6} \mathrm{Al}$ respecto puede consultarse Reglamento de las Asambleas Municipales del Poder Popular.
}

que se realizan al menos una vez al año (Santos Cid y Peralta de Valle, 2003).

Este es el punto crítico del análisis, por lo expuesto en el procedimiento se advierte que la actividad presupuestaria local (dígase diseño, ejecución y control) es ajena a los ciudadanos, es una actividad personalísima de los organos del Estado; y aun y cuando es atribución de la AMPP elaborar el proyecto presupuestario, la aprobación final se convierte en un acto formal en la medida en que el documento es modificado y aprobado en otras instancias superiores (Pérez Hernández y Prieto Valdés, 2004). En igual sentido el ensayista Julio César Wanche (2012: 76) plantea: "La aprobación de los presupuestos municipales deviene un acto formal y no un instrumento de iniciativa estatal local. Con ello, se limita el cumplimiento del rol del delegado y se minimiza su figura - a su vez, se resta sustancia al proceso del que forma parte- y mantiene la transferencia de la soberanía popular hacia la sede del gobierno".

En sus análisis Díaz Legón (2015) considera oportuno la publicidad de la actividad gubernamental, que se le informe a la población acerca del estado de la hacienda pública, que la ciudadanía se informe de todo lo concerniente a los ingresos y gastos públicos, en fin introducir gradualmente prácticas del presupuesto participativo.

La vocación democrática y participativa local tiene en su génesis el manejo y control por parte de la ciudadanía del los fondos públicos, teniendo en cuenta que éste es el motor que mueve la actividad pública. Por lo tanto para impulsar un proyecto de desarrollo local el Estado cubano debe superar importantes escollos relacionados con la participación ciudadana y los fondos públicos, que ya en la última década de siglo XX comenzaban a ser señalados como limitaciones para el desarrollo a escala territorial entre ellos destacan:

- la centralización y verticalismo en la toma de decisiones,

- falta de autonomía económica y financiera de los gobiernos municipales,

- la insuficiente participación social en la toma de decisiones.

El VI Congreso del Partido Comunista de Cuba (PCC) marca un antes y un después en la concreción de una política de desarrollo local ${ }^{7}$. Los procesos de descentralización ocupan un lugar destacado

\footnotetext{
${ }^{7}$ Una parte considerable de las políticas que conforman los lineamientos tiene una relación directa o indirecta con el desarrollo local de ahí que el VI congreso del PCC y la aprobación de los lineamientos marque una étapa importan-
} 
en las remodelaciones que proponen los lineamientos (lin.) del VI congreso del PCC del 1 de noviembre de 2010 trazados en la cita partidista (Palacios, 2012):

- Se asignan funciones estatales a las administraciones provinciales y municipales, sin llegar a interferir directamente la gestión empresarial (lin.35).

- Se promueve el desarrollo de proyectos locales conducidos por los Consejos de la Administración Municipal (CAM).

- La creación de micro-industrias y centros de servicios, vinculando la gestión de los mismos a entidades enclavadas en el municipio (lin.37) y otorgando un peso fundamental en la conducción de los proyectos a los (CAM).

- Creación de fondos de estimulación salarial descentralizados a nivel empresarial (lin.19). Integración de las pequeñas procesadoras de alimentos a nivel local con la gran industria.

La segunda limitación señalada (el alto nivel de centralización de los recursos financieros y la insuficiente autonomía económica y financiera de los municipios) encuentra una salida bastante loable en el nuevo proyecto económico. En este sentido el sistema tributario es utilizado como vía para solventar la necesidad acuciante de financiamiento que presentan las localidades paras su desarrollo.

En el título III de la Ley 113 de 2012, Art. 314 se regula una contribución para el desarrollo sostenible de los municipios, que grava los ingresos por la comercialización de bienes o prestación de servicios que obtengan las empresas, sociedades mercantiles y cooperativas por sí mismas y por sus establecimientos en cada territorio.

El tipo impositivo de esta contribución quedará determinado por la ley anual del presupuesto. La base imponible estará constituida por la totalidad de los ingresos provenientes de la venta de bienes y la prestación de servicios de los sujetos pasivos en este caso las empresas, las sociedades mercantiles de capital totalmente cubano y las cooperativas, por sus establecimientos.

Estas transformaciones implican un giro a una política centrista que constituyó por más de cuatro décadas el eje de la economía cubana, empero resulta cuestionable hasta qué punto esta transferencia de poder constituye una descentralización.

te para el desarrollo local en Cuba. Véase Díaz Canel, M. (2011).
Efectivamente, como bien aclara la ciencia política "(...) lo fundamental de la descentralización sería su dimensión política, es decir, el constituir una redistribución espacial del poder democrático en provecho de las comunidades locales" (Boisier, 2007:38). El propio Boisier considera que la descentralización es equivalente a la democracia y al proceso de democratización del Estado, en tanto posibilita el control y la participación de los ciudadanos en la actividad de gobierno. Descentralización sin participación es pura ficción, enfatiza el citado autor.

No basta con descentralizar funciones y otorgar a los municipios elevados niveles de recursos económicos y financieros si no existe una adecuada gestión de gobierno que involucre con un alto contenido democrático a todos los grupos sociales de la comunidad. No hay verdadero desarrollo si los ciudadanos, los beneficiarios del desarrollo no participan en el diseño, ejecución y control de las iniciativas de desarrollo.

En la Cuba de nuestros días, el desarrollo integral demanda crecimiento de la economía nacional (entendido en sentido amplio, como desarrollo humano y no sólo económico) pero, también, fortalecimiento de las instituciones y mecanismos jurídicos participativos, creación de las vías que permitan una mayor participación ciudadana en la toma de decisiones.

El desarrollo local propone un mayor acercamiento de los órganos de poder a los ciudadanos, que en gran medida facilitará la participación si se estima, tal como fuera defendido por Aristóteles y Montesquieu $^{8}$, que la verdadera participación y protagonismo del pueblo se da en espacios geográficos pequeños (Jiménez Morales, 2009). Empero sería éste un importante paso pero no suficiente, se hace necesario no solo perfeccionar las instituciones jurídicas existentes sino crear las necesarias para lograr una adecuada articulación participativa entre los diferentes actores locales.

Si bien el Estado cubano ha dado pasos importantes en lograr mayores niveles democráticos en los municipios (creación de los Órganos Locales del Poder Popular y los Consejos Populares) estos cambios no han constituidos nuevos canales en el sentido de lograr mayor acceso popular a la toma de

\footnotetext{
${ }^{8}$ Respecto al tema y concretamente con relación a $\mathrm{Cu}$ ba, ver a M. Prieto y L. Pérez (1996), "Cuba; las relaciones Estado-individuo: garantías de los derechos, municipio y legitimidad. Propuesta jurídica para su perfeccionamiento",. Destaca la importancia del municipio como base del aparato estatal y el ámbito más genuino de participación popular, así como concederle mayor autonomía administrativa y de nuevas formas de participación que propicien un aumento de autoridad de los órganos del Poder popular.
} 
decisiones.

Bajo tales presupuestos crear o perfeccionar los canales participativos que permitan a los ciudadanos tomar parte en el destino y control del presupuesto asignado a los municipios para el desarrollo local en el actual contexto cubano es una tarea que requiere de urgencia.

\section{El presupuesto participativo: una propuesta para el caso cu- bano}

El punto de partida de esta propuesta es el reconocimiento de la realidad cubana. En el caso de Cuba no se trata de importar los modelos de presupuesto participativo tal y como han sido concebidos en otros países, tales intentos casi siempre nos han dejado el sin sabor del fracaso y es que los problemas se parecen pero no las soluciones.

Por otra parte la propuesta no se sustenta en la creación de nuevas estructuras e instituciones, sino, en introducir en las existentes, los objetivos, principios y fundamentos del presupuesto participativo.

Es por ello que se propone utilizar la actual estructura política administrativa municipal con especial énfasis a las estructuras y procesos que por estar más cerca de los ciudadanos facilitan la participación directa en la aprobación, ejecución y control del presupuesto local dígase: la rendición de cuenta, la figura del delegado y la estructura del Consejo Popular.

Estas estructuras e instituciones constituyen una fortaleza para la actividad participativa, en primer lugar porque es la estructura del Estado y del gobierno más cercana a los ciudadanos y sus problemáticas, en segundo lugar aglutina, en su concepción a gran parte de los actores sociales de la comunidad (organizaciones políticas y de masa, entidades estatales y privadas, ciudadanos) y por último constituye un fluido canal de comunicación entre la base y el máximo órgano de poder local Asamblea Municipal del Poder Popular (AMPP).

Al respecto Villavella Armegol (2004) enfatiza en el doble papel del delegado como representante de los ciudadanos y miembro del máximo órgano de poder local; por una parte ejercen el mandato que le han otorgado los electores y por otra parte constituye un puente de doble vía entre la comunidad y el órgano de poder, que un sentido traslada las necesidades, opiniones de los electores y en el otro les informa y orienta sobre la política seguida por la Asamblea para dar solución a las diversas pro- blemáticas.

Por su parte Pérez y Prieto (2004) consideran como principales fortalezas del delegado su incidencia en las soluciones participativas y su alcance al control administrativo.

En cuanto a la rendición de cuenta el propio Villavella Armegol (2004) reconoce la importancia de este mecanismo participativo de control y lo califica como el momento más importante de la democracia municipal en tanto el pueblo ejerce gobierno de forma directa, trazando proyecciones y consensuando políticas.

En lo tocante a los Consejos Populares basta recordar las palabras del líder de la Revolución Cubana compañero Fidel Castro Rus para comprender la autoridad de este órgano dentro de la comunidad: "no administran nada, no distribuyen nada, pero tienen que ver con todo lo que esté mal allí (...)" (Castro Ruz, 1990:2).

Tomando en consideración los fundamentos anteriormente expuestos proponemos la siguiente metodología para la instrumentación del presupuesto participativo en Cuba.

\section{Características de la metodo- logía}

\section{Carácter cíclico: Al inicio de cada pro- ceso se evaluará la ejecución del ante- rior}

El proceso de análisis y discusión quedará dividido en 3 etapas que se desarrollarán bajo el principio de ordenación territorial y temática.

- Vinculación de mecanismos de participación directa con representativa.

- Las demandas partirán de dinámicas territoriales a nivel de barrios.

- No reglamentado.

- Control por medio de la rendición de cuenta.

- Efectos vinculantes de las propuestas aprobadas en los diferentes niveles.

Se debatirá sobre una parte del presupuesto local, especificamente Los ingresos por Concepto de Recaudación para el Desarrollo Local, que regula el art. 314 de la Ley 113 "Del Sistema Tributario". 


\section{La estructura participativa}

La propuesta estructural participativa tal como se ha concebido en diversas metodologías en América (Porto Alegre, Argentina, Uruguay) y extendidas a Europa (España, Francia) se sustenta en niveles que van desde lo microlocal (barrio, cuadra, distrito, parroquia) hasta niveles territoriales de mayores dimensiones (ciudad, municipio). Esta estructura toma la forma piramidal donde en la base están los habitantes de los barrios, los diferentes grupos sociales interactuando mediante reuniones deliberativas, participando de forma directa. En el nivel superior de la pirámide generalmente está un órgano representativo, que puede o no ser el encargado de tomar la decisión final, pero que generalmente constituye la cumbre del proceso (Ives, 2005).

Con esta estructura se logra una articulación entre el nivel micro y el macro, por demás permite la articulación de la participación directa con la representativa.

\section{La metodología se estructura en tres niveles:}

\section{Primer nivel}

El nivel micro local coincide con las áreas existentes para los procesos de rendición de cuenta y el proceso se desarrollará en este mismo espacio participativo. Como habíamos expuesto con anterioridad esto evitará colapsar el proceso con nuevos órganos y funcionarios, así como crear nuevas ventanas burocráticas.

Como ocurre en los procesos de rendición de cuenta los electores de una circunscripción ${ }^{9}$ se agrupan por áreas para efectuar sus planteamientos, necesidades y problemáticas comunitarias. La participación será directa y personal.

Participarán representantes del órgano local del gobierno (AMPP) y del (CAM) para lograr la articulación entre el nivel micro y el nivel local, y facilitar que los gobernantes rindan cuenta a los ciudadanos.

\footnotetext{
${ }^{9}$ La circunscripción es una forma de organizar el municipio de cara a los procesos electorales, en cada una de estas unidades territoriales se elige un delegado que forma parte de la AMPP. Un Consejo popular está integrado por varias circunscripciones $(8,10,11,12)$ en dependencia de la extensión territorial del consejo y la cantidad de población entre otras cuestiones. Para asumir la rendición de cuenta cada circunscripción se divide en áreas proporcionalmente a la cantidad de población. Muchas veces se asumen los criterios de divisiones por barrios, calles o cuadras de manera que un área coincidan intereses sociales, económicos.
}

\section{Segundo nivel}

El segundo nivel es el del Consejo Popular. Si bien el nivel anterior se caracteriza por la participación directa, aquí la participación tiene carácter representativo. Las circunscripciones que conforman el Consejo Popular estarán representadas por ciudadanos previamente electos en el nivel anterior. El número de representantes será en un porciento proporcional a la cantidad de participantes.

Serán invitados todos los factores del Consejo Popular (dirección de las organizaciones políticas y de masas, directivos de las entidades enclavadas en la comunidad) y representantes del Consejo de la Administración Municipal (CAM) en el municipio, según sea el vínculo de éstos últimos con las temáticas de las prioridades aprobadas en el primer nivel.

\section{Tercer Nivel}

El tercer nivel lo conforma la Asamblea Municipal del Poder Popular (AMPP). Este será el órgano encargado de tomar la decisión final en base a las propuestas hechas por los ciudadanos en las asambleas de rendición de cuenta.

La participación es representativa, los delegados representarán a sus electores y solo ellos tendrán derecho al voto.

\section{El proceso del PP}

El proceso se desarrollará en tres fases. Cada fase tendrá su despliegue dentro de un nivel de manera que la fase uno se desarrolla en el primer nivel, la dos en el nivel dos y la tres en el tercer nivel.

\section{Primera fase del proceso}

Esta fase tiene como objetivo principal la definición de las prioridades para el presupuesto y esto se hará viable por medio de las asambleas de rendición de cuenta que a su vez se desarrollarán en tres $\operatorname{ciclos}^{10}$.

Consideramos que estas asambleas deben desarrollarse en un proceso colegiado, que logre una sinergia entre todos los participantes. Los principios que deben primar serán el del debate profundo entre la ciudadanía y los gobernantes acerca de las

\footnotetext{
${ }^{10}$ Los procesos de rendición de cuenta se efectúan al menos tres veces al año y tienen derecho a participar todos los electores.
} 
necesidades y prioridades de la comunidad y la toma de decisiones conjuntas.

El primer ciclo de reuniones debe ser un espacio para que los órganos de poder rindan cuenta sobre la ejecución del presupuesto del año anterior, informar como marcha la del año en curso y su proyección para el próximo. La rendición de cuenta es el mecanismo de control ciudadano más utilizado en la mayoría de los modelos por que le imprime un carácter cíclico al proceso (comienza un ciclo evaluando el anterior), y por que constituye un medio de evaluación, de retroalimentación y de legitimación.

Este será el espacio para que el ejecutivo local, CAM, presente sus propuestas de prioridades y su proyección presupuestaria con la finalidad de que sean analizadas y estudiadas por lo ciudadanos.

En el segundo ciclo de reuniones comenzarán las propuestas de los ciudadanos acerca de las prioridades, necesidades y criterios para la distribución de los recursos. Todas las propuestas deben ser recogidas y sometidas a votación.

En el tercer ciclo de reuniones se concretarán las propuestas y se elegirán las personas que representarán a la circunscripción ente el Consejo Popular.

\section{Segunda fase}

Esta será una fase representativa donde participarán los elegidos en las reuniones de rendición de cuenta, participarán además los delegados, miembros del CAM y especialistas según áreas temáticas que tengan relación con las prioridades y demandas de los ciudadanos definidas en la primera fase, pueden ser invitados factores de la comunidad.

En un espacio de debate y discusión entre los participantes se elaborará la propuesta de prioridades entre las áreas temáticas (acueducto, comunicaciones, viales). Esta propuesta será sometida a votación y una vez aprobada constituirá la demanda de prioridad presupuestaria del Consejo Popular.

En esta fase resulta de gran importancia la participación de los especialistas de las áreas temáticas en tanto facilitará un debate más entendido que redundará en una propuesta de mayor rigor y fundamentos técnicos, aunque finalmente la aprobación del documento será arbitrio de los delegados y representantes.

Para garantizar que el presupuesto sea expresión de la voluntad popular el debate debe ceñirse a las propuestas venidas de las reuniones de rendicion de cuenta. El debate argumentativo y democrático propiciará que sean promovidas las propuestas más factibles, necesarias y urgentes, pero nunca nuevas propuestas. Desde este punto de vista las propuestas de las asambleas de base tienen efecto vinculante.

Una vez aprobadas las prioridades presupuestarias por los Consejos Populares estas serán presentadas al CAM quien tendrá a cargo la elaboración de la propuesta presupuestaria para el municipio.

\section{Tercera fase}

La aprobación definitiva del presupuesto corresponderá a la Asamblea Municipal del Poder Popular (AMPP). El CAM presentará a la AMPP el plan presupuestario para su aprobación mediante el voto mayoritario de sus miembros.

La AMPP mediante sus acuerdos instrumentará la ejecución del presupuesto aprobado, mientras que será responsabilidad del CAM la ejecución. Por otra parte al pie de las facultades legales que le son conferidas a la AMPP puede ejercer control sobre el CAM y este deberá rendir cuenta de su actividad cuando la asamblea se lo solicite.

\section{Conclusiones}

La autonomía económica y financiera es una necesidad para poder potenciar el desarrollo local de los municipios cubanos. A tono con esta necesidad la nueva Ley del Sistema Tributario (Ley 113/2012), grava los ingresos de las empresas, sociedades mercantiles y cooperativas con vistas a que tales aportes financien parte de los proyectos de desarrollo local en los municipios cubanos.

La importancia de este tributo recae en que lo recaudado constituirá ingresos cedidos a los presupuestos locales de cada municipio, contribuyendo así al financiamiento de los gastos corrientes del territorio y al auspicio de actividades dirigidas a garantizar el desarrollo sostenible en cualquier sector de la economía y del ámbito social. Como complemento necesario e indispensble a esta medida descentralizadora en menester instrumentar los mecanismos que posibiliten que todos los actores sociales tomen parte en la ejecución y control del presupuesto local.

El presupuesto participativo resulta una práctica participativa viable a los efectos de lograr la participación de los ciudadanos en la construcción de los proyectos de desarrollo local a partir de la decisión y del control que pueden ejercer sobre el erario 
públicos para el desarrollo territorial. A tales fines la metodología que asume el presupuesto participativo de Porto Alegre resulta factible y avocada a las necesidades y condiciones de la municipalidad cubana. La referida metodología puede ordenarse a partir de las estructuras e instituciones participativas locales, en este sentido se evitaría congestionar los territorios con nuevas estruturas y órganimos que pueden redundar en la burocratización de los procesos, por otra parte se revitalizarían las instituciones y procedimeinto participativos locales.

\section{Referencias}

Boisier, S. (2007). Territorio Estado y Sociedad en Chile. La Dialéctica de la Descentralización. Entre la Geografía y la Gobernabilidad. Doctoral, Universidad de Alcalá de Henares.

Borja, J. (1987). Descentralización del Estado. Movimiento Social y Gestión Local. FLACSOCLACSO, Santiago de Chile.

Cárdenas, N. (2002). El desarrollo local su conceptualización y procesos. Provincia, (8):53-76.

Castro Ruz, F. (1990). Intervención en el periodo de sesiones de la tercera legislatura de la Asamblea Nacional.

De Souza, U. y Genro, T. (1999). Presupuesto Participativo. La experiencia de Porto Alegre.

Díaz Legón, O. (2015). Descentralización fiscal y desarrollo local en Cuba. Ideas preliminares (desde el Derecho) para la articulación del proceso. En Pérez Hernández, L. y Díaz Legón, O., editores, Â¿Qué municipios queremos? Respuestas para Cuba en clave de desarrollo local y descentralización, pp. 293-309. Editorial UH, La Habana.

Esparcia, J. y Escribano, J. (2014). Capital social relacional en áreas rurales: un estudio a partir del análisis de redes sociales. En Cortizo, J., Redondo, J. M., y Sánchez, M. J., editores, De la Geografía Rural al Desarrollo Local, Homenaje a Antonio Maya, pp. 215-230. Universidad de León.

Finot, I. (2001). Descentralización en América Latina: teoría y práctica. Serie Gestión Pública, № 12 (LC/L.1521-P), CEPAL, Santiago de Chile.

Gallicchio, E. y Camejo, A. (2005). Desarrollo local y descentralización en América Latina: nuevas alternativas de desarrollo. Centro Latinoamericano de Economía Humana.
Gallichio, E. (2004). El desarrollo local:Ầ cómo combinar gobernabilidad, desarrollo económico y capital social en el territorio? Cuadernos del CLAEH, 27(89):55-68.

Ganuza Fernández, E. y Gómez Fortes, B. (2008). Control político y participación en democracia: los presupuestos participativos. Fundación Alternativas.

Guzón Camporredondo, A. (2015). A proposito del desarrollo local en Cuba. En Pérez Hernández, L. y Díaz Legón, O., editores, Â¿Qué municipios queremos? Respuestas para Cuba en clave de desarrollo local y descentralización, pp. 104-116. Editorial UH, La Habana.

Jiménez Morales, C. (2009). El Distrito en el Estado Cubano. Premisas para su ordenación jurídica. Doctoral, Universidad de Oriente.

Palacios, J. C. (2012). La reforma de la economía cubana. Evaluación de su potencial impacto en el crecimiento económico. Papeles de Europa, 24:16-53.

Palma, E. (1983). La descentralización desde una perspectiva política. LPES, Documento CPRD D/90, Santiago de Chile.

Palma, E. (1989). Las nociones de centralización y descentralización. ILPES, Documento CPS 48, Santiago de Chile.

Pérez Hernández, L. y Prieto Valdés, M. (2004). Estado, Gobierno y Administración, diferenciación conceptual a propósito de la Ley de los Municipios. En Temas de Derecho Constitucional Cubano, pp. 199-220. Editorial Félix Varela, Cuba.

Santos Cid, C. M. y Peralta de Valle, E. (2003). Sistema presupuestario. En Administración financiera del Estado cubano, Centro de Estudios Contables, Financieros y de Seguros, pp. 77-119. La Habana.

Sintomer, Y. (2005). Los presupuestos participativos en Europa: retos y desafíos. Revista del clad Reforma y Democracia, 31(1):1-17.

Vázquez Barquero, A. (2000). Desarrollo económico local y descentralización: aproximación a un marco conceptual. Informe LC/R.1964. Proyecto Regional de Desarrollo Económico Local y Descentralización. CEPAL/GTZ, Santiago de Chile.

Villavella Armegol, C. (2004). El modelo Estatal Municipal Cubano. Breves apreciaciones sobre sus instituciones. En Temas de Derecho Constitucional Cubano, pp. 199-203. Editorial F\{é\}lix Varela, La Habana. 
Von Haldenwang, C. (1990). Hacia un concepto politológico de la descentralización del Estado en América Latina. EURE. Revista Latinoamericana de Estudios Urbano Regionales, 16(50):61.

Wanche, J. C. (2012). La participación ciudadana en el Estado cubano. En Temas de Derecho Constitucional Cubano, volumen 70, pp. 69-79. 